\title{
Comparison of penile prosthesis types' complications: A retrospective analysis of single center
}

\author{
Erdem Kisa, Mehmet Zeynel Keskin, Cem Yucel, Murat Ucar, Okan Yalbuzdag, Yusuf Ozlem Ilbey \\ Tepecik Training and Research Hospital, Urology Department, Izmir (Turkey).
}

\begin{abstract}
Summary Objectives: The aim of this study was to compare clinical outcomes and complication rates associated with semirigid (malleable) and inflatable penile prostheses (PPs) and investigate the factors that influence these complications.

Material and methods: The records of 131 patients who had undergone penile prosthesis implantation (PPI) in our clinic due to erectile dysfunction (ED) between January 2010 and March 2019 were retrospectively reviewed. The initial surgery included 116 primary implants and 15 men had two revision operations. Patients were assigned to two groups as semirigid (malleable) PPI (group 1) and inflatable PPI (group 2) patients, and obtained data were compared across these two groups.

Results: Group 1 included 93 patients, while Group 2 included 38 patients. Postoperative complication rates of Group 1 were $8.6 \%(n=8)$, and Group 2 were $21 \%(n=8)$, and the comparison of postoperative complication rates revealed a statistically significant difference between the two groups ( $p=0.025)$.

The majority of these complications (50\%) was constituted by mechanical failure associated with inflatable PPs. When patients were further segregated as those with and without diabetes type 2 (DM) and those who had and had not undergone radical pelvic surgery (RPS), the comparison of complication rates across these subgroups did not yield any significant difference.

Conclusions: We determined in this study that semirigid (malleable) PPs were associated with lower complication rates compared to the inflatable group, particularly with regard to mechanic failure, and that DM and history of RPS did not make a difference in complication rates in patients planned to undergo PPI.
\end{abstract}

KEY WORDS: Penile prosthesis; Penile prosthesis implant; Erectile dysfunction; Impotence; Radical surgery; Satisfaction.

Submitted 1 June 2019; Accepted 1 September 2019

\section{INTRODUCTION}

Penile prosthesis implantation (PPI) treatment has been offered for over 40 years with high surgical success in patients with erectile dysfunction (ED) who either do not respond to pharmacological treatments such as oral phosphodiesterase type 5 (PDE5) inhibitors and less invasive intracavernosal vasocactive agents or reject these treatments (1). Penile prostheses (PPs) are categorized into two groups as non-inflatable and inflatable prostheses. Non-inflatable PPs are also referred to as "semirigid (mal- leable)". Inflatable prostheses are further classified into two groups as two-piece and three-piece prostheses. Although semirigid (malleable) PPs are more durable and less expensive, they can experience more erosion as they are constantly rigid. On the other hand, inflatable PPs allow use in flaccid and erect states and offer cosmetic advantage, however, possessing a more complex structure may result in mechanical failure over time (2-6). Currently, two-piece and three-piece PPs constitute 75\% of PPI surgeries worldwide, while in our country, semirigid (malleable) PPs are used at higher rates due to the reimbursement conditions of the social security institution and the higher cost of inflatable PPs (7-11).

Although PPI surgery is associated with patient and partner satisfaction, certain complications may arise during and after this operation (12-14). These include; intraoperative complications such as urethra perforation, cavernosal crossover, and crural perforation, as well as complications encountered in the postoperative period such as wound site infection, hematoma, lower urinary tract symptoms, bending during intercourse, breakage of the prosthesis, concorde deformity, and mechanical failure, particularly in multi-piece types. Among factors that influence these complications, the role of diabetes type 2 (DM) and history of radical pelvic surgery (RPS) has been contended in the literature (10, 15-17).

The aim of this study was to evaluate the clinical outcomes and surgical complications after PPI performed at our institution on patients with various causes of ED, compare complication rates associated with semirigid (malleable) and inflatable PPs, and investigate the factors that influence these complications.

\section{MATERIALS AND METHODS}

Approval of the institutional ethics committee was obtained. We retrospectively reviewed the records of 116 men with ED who had 131 penile prostheses implanted in our clinic due to end-stage ED between January 2010 and March 2019. The initial surgery included 115 primary implants and one revision case, who had undergone the initial operation at another institution. A further 15 men had two revision operations. Three patients with insufficient data and two cases, who had PPs implanted at another centre and demanded removal without replacement, were excluded from the study. For all the patients, demographic characteristics, duration of ED time, size of implanted PP, complications data, and patient satisfaction 
were evaluated. Patients were assigned to two groups as semirigid (malleable) PPI (group 1) and inflatable PPI (group 2) patients, and obtained data were compared across these two groups.

Indications for PPI were failure or intolerance of medical treatment, confirmation of ED by Doppler ultrasound, and severe ED. All men routinely underwent medical and psychiatric consultation before the surgery. The operative field was disinfected with povidone-iodine $10 \mathrm{~min}$ before the surgical intervention. Preoperative antibiotic prophylaxis, such as vancomycin, was given the night before the surgery and for 3 days postoperatively. Oral antibiotic prophylaxis with ciprofloxacin was continued through the 7 th postoperative day. All the PPs were implanted through penoscrotal incisions. The implant and surgical sites were irrigated with gentamicin in saline prior to implantation. The corpus cavernosum usually was dilated with Hegar dilators, though an Otis urethrotome was deemed necessary in two cases. A Foley catheter was inserted at the end of the procedure and removed 1 day later. The patients were discharged 1-2 days postoperatively.

Surgical complications were recorded in detail. Peroperative and postoperative complications were evaluated separately and compared between the groups. Postoperative complications were divided into two groups as 'early' (complications occurring within 30 days of surgery) and late (complications occurring after 30 days of surgery).

Prosthesis function was evaluated 1 month after surgery and then annually until lost to follow-up. Our patients were asked during control visits if they were satisfied, or unsatisfied with the prosthesis in general. They were evaluated at or within 12 months of the postoperative period, in most cases through face-to-face interviews. However, in some patients who failed to visit the clinics, follow-up was assessed through telephone interviews.

\section{Statistical analyses}

The groups were assessed for normal distribution using the Shapiro Wilk test. Statistical difference between the groups were analyzed with independent sample t test Mann Whitney U test. Chi-square test was used for cross comparison. A p-value $<0.05$ was considered statistically significant. All analyses were made by IBM SPSS V22.

\section{RESULTS}

Data obtained from all patients were reviewed to determine duration of ED time, causes of ED, pre-prosthetic treatment of primary patients, type of implanted PP, size of implanted PP, perioperative and postoperative complications (Table 1). The most common factor implicated in the ED etiology of patients was DM with a rate of $41.2 \%$ ( $\mathrm{n}=54$ ), followed by RPS with a rate of $20.6 \%$ (n = 27). Of $54 \mathrm{DM}$ patients, $26(48.1 \%)$ were on oral antidiabetics and $28(51.8 \%)$ on insulin therapy. Overall perioperative complication (urethra perforation and cavernosal crossover) rate was $1.5 \%(n=2)$. In one of these, where urethra perforation had been encountered during the cavernousal dilation stage of PPI and the procedure had been postponed, only one side of the semirigid (malleable) PP could be implanted in the second surgical ses- sion due to difficulty in dissection. All perioperative complications were resolved during surgery, and the operations were completed successfully. The overall postoperative complication rate was $12.2 \%(\mathrm{n}=16)$.

\section{Table 1.}

Demographics; duration, etiology and treatment of erectile disfunction (ED); characteristics, complications and satisfaction of penile prostheses (PPs).

\begin{tabular}{|c|c|}
\hline Number of patients & 131 \\
\hline Median age, year (min-max.) & $59(28-74)$ \\
\hline Mean \pm SD & $58.4 \pm 8.3$ \\
\hline Median duration of ED time, year (min-max.) & $3(1-21)$ \\
\hline Mean $\pm S D$ & $4 \pm 3.6$ \\
\hline \multicolumn{2}{|l|}{ Causes of ED of primary patients, $n,(\%)$} \\
\hline Idiopathic & 22 \\
\hline \multicolumn{2}{|l|}{ Comorbidity } \\
\hline DM (Diabetes type 2) & $54(41.2 \%)$ \\
\hline Hypertension & 26 \\
\hline Myocardial infarction & 11 \\
\hline By-pass surgery & 5 \\
\hline Chronic obstructive pulmonary disease & 2 \\
\hline Cerebrovascular occlusion & 1 \\
\hline \multicolumn{2}{|l|}{ RPS (Radical pelvic surgery) } \\
\hline Radical prostatectomy & $24(18.3 \%)$ \\
\hline Radical cystectomy & $3(2.2 \%)$ \\
\hline - Pelvic radiotherapy & 7 \\
\hline - Priapism & 1 \\
\hline - Peyronie's disease & 9 \\
\hline Penis fracture & 1 \\
\hline \multicolumn{2}{|l|}{ Pre-prosthetic treatment of primary patients } \\
\hline Phosphodiesterase 5 (PDE5) inhibitors & 114 \\
\hline On-demand & 101 \\
\hline Daily & 13 \\
\hline Cavernosal injection & 1 \\
\hline Vascular surgery & 1 \\
\hline \multicolumn{2}{|l|}{$\overline{\mathrm{PPI}}$} \\
\hline - Primany implants & $116(88.5 \%)$ \\
\hline - Revision implants & $15(11.4 \%)$ \\
\hline \multicolumn{2}{|l|}{ Type of implanted PP, n, (\%) } \\
\hline Semi-rigid (Malleable) prostheses & $93(70.9 \%)$ \\
\hline Inflatable prostheses & $38(29 \%)$ \\
\hline Two-piece & $36(94.7 \%)$ \\
\hline Three-piece & $2(5.2 \%)$ \\
\hline \multicolumn{2}{|l|}{ Size of implanted PP, n, (\%) } \\
\hline - Median size, diameter, cm (min-max.) & $10(9-13)$ \\
\hline - Median size, length, cm (min-max.) & $18.5(12-25)$ \\
\hline Perioperative complications, $n(\%)$, Note & $2(1.5 \%)$ \\
\hline - Urethra perforation & 1, During dilatation, postpone \\
\hline - Cavernosal crossover & 1, During dilatation \\
\hline Crural perforation & 0 \\
\hline Postoperative complications & $14(10.6 \%)$ \\
\hline \multicolumn{2}{|l|}{ - Early } \\
\hline Superficial wound infection & 4, Resolved with antibiotherapy \\
\hline Hematoma located on scrotum & 1, Resolved at follow-up \\
\hline \multicolumn{2}{|l|}{ Late } \\
\hline Bending during intercourse & 1, Revision \\
\hline Lower urinary tract symptoms & 1, History of TURP \\
\hline Penile prosthesis breakage & 2, Revision \\
\hline Concord deformity & 1, Revision \\
\hline Mechanical failure & 4, Revision \\
\hline Overall complications & $16(12.2 \%)$ \\
\hline \multicolumn{2}{|l|}{ Patient satisfication, n (\%) } \\
\hline Satisfied & $105 / 131(80.1 \%)$ \\
\hline Not satisfied & $16 / 131(19.8 \%)$ \\
\hline
\end{tabular}


Revision surgery was needed for $11.4 \%$ (15/131) of the PPs inserted. Of these 15 patients who underwent revision PPI, 12 had undergone the primary surgery at our clinic and three at external centers. The median time until PPI revision was determined as 36 months (1-192 months). Overall, 80.1\% (105/131) of the men were satisfied with the results.

Group 1 included 93 patients, while Group 2 included 38 patients. The comparison of data from Group 1 and Group 2 patients have been summarised in Table 2. In Group 1, one patient had to be implanted with differentsized PPs on the right and left sides, whereas in Group 2, six patients were implanted with PPs of discrepant sizes. Postoperative complication rates of Group 1 were 8.6\% (n $=8$ ), and Group 2 were $21 \%(\mathrm{n}=8)$, and the comparison of postoperative complication rates revealed a statistically significant difference between the two groups $(\mathrm{p}=0.025)$.

Table 2.

Study outcomes by type of prosthesis.

\begin{tabular}{|c|c|c|c|}
\hline & $\begin{array}{c}\text { Semirigid PPI } \\
\quad(n=93)\end{array}$ & $\begin{array}{c}\text { Inflatable PPI } \\
(n=38)\end{array}$ & p \\
\hline Median aǵe, year (min-max.) & $59(38-74)$ & $61(28-69)$ & 0.667 \\
\hline Mean $\pm S D$ & $58.6 \pm 7.5$ & $58.1 \pm 9.8$ & \\
\hline Median duration of ED time, year (min-max.) & $3(1-20)$ & $2(1-21)$ & 0.229 \\
\hline Mean $\pm S D$ & $4.2 \pm 3.5$ & $3.7 \pm 4$ & \\
\hline \multicolumn{4}{|l|}{ Size of implanted PP, n, (\%) } \\
\hline Median size, diameter, cm (min-max.) & $10(9-13)$ & $18.5(12-25)$ & 0.256 \\
\hline Median size, length, cm (min-max.) & $12.5(12-12.5)$ & $19(14.5-22)$ & 0.349 \\
\hline Perioperative complications, $n(\%)$ & $2(2.1 \%)$ & 0 & 0.502 \\
\hline Urethra perforation & $1(1 \%)$ & 0 & \\
\hline Cavernosal crossover & $1(1 \%)$ & 0 & \\
\hline Crural perforation & 0 & 0 & \\
\hline Postoperative complications & $6(6.4 \%)$ & $8(21 \%)$ & 0.025 \\
\hline \multicolumn{4}{|l|}{ - Early } \\
\hline Superficial wound infection & 2 & 2 & \\
\hline Hematoma located on scrotum & 0 & 1 & \\
\hline \multicolumn{4}{|l|}{ Late } \\
\hline Bending during intercourse & 1 & 0 & \\
\hline Lower urinary tract symptoms & 1 & 0 & \\
\hline Penile prosthesis breakage & 2 & 0 & \\
\hline Concord deformty & 0 & 1 & 0.074 \\
\hline Mechanical failure & 0 & 4 & \\
\hline Overall complications & $8(8.6)$ & $8(21 \%)$ & \\
\hline
\end{tabular}

Table 3.

Comparison of overall complication rates of patients with and without diabetes type 2 (DM).

\begin{tabular}{|lccc|}
\hline & $\begin{array}{c}\text { DM } \\
(\mathbf{n}=\mathbf{7 3})\end{array}$ & $\begin{array}{c}\text { DM } \\
\text { ( } \mathbf{n}=\mathbf{5 8})\end{array}$ & p \\
\hline No complication & $66(90.4 \%)$ & $49(84.4 \%)$ & 0.421 \\
\hline Overall complications & $7(9.5 \%)$ & $9(5.5 \%)$ & \\
\hline
\end{tabular}

Table 4.

Comparison of overall complication rates of patients with and without radical pelvic surgery (RPS).

\begin{tabular}{|lccc|}
\hline & $\begin{array}{c}\text { DM } \\
(\mathbf{n}=\mathbf{7 3})\end{array}$ & $\begin{array}{c}\text { DM } \\
\text { (n= 58) }\end{array}$ & p \\
\hline No complication & $86(86 \%)$ & $29(93.5 \%)$ & 0,356 \\
\hline Overall complications & $14(14 \%)$ & $2(6.4 \%)$ & \\
\hline
\end{tabular}

Among postoperative complications, mechanical failure was detected in four patients, all of whom were Group 2 patients who had inflatable (two-piece) PPIs.

When patients were further segregated as those with and without DM and those who had and had not undergone RPS, the comparison of complication rates across these subgroups did not yield any significant difference (Tables 3, 4).

\section{Discussion}

PPI has been used effectively in patients who do not respond to oral therapies such as PDE5 inhibitors and to intracavernosal injection therapy (1). Although this treatment method offers high patient and partner satisfaction, it may be associated with certain perioperative and postoperative complications (2-13). Among these complications, most notable are the PP infections and mechanical failure that arise in the postoperative period. In the recent years, technological advancements in PPs and advances in the surgical procedure technique have resulted in a partial decrease in these rates (18). Although inflatable PPs are utilized more commonly across the world, semirigid (malleable) PPs have been utilized at greater rates in our country due to low economic status of the patients, high cost of inflatable PPs, and reimbursement conditions of the social security institution (7-11). In this study, we aimed to compare the complication rates associated with semirigid (malleable) and inflatable PPs that we implant at our clinic as well as to compare these rates between patients with and without DM and patients with and without history of RPS. The two groups demonstrated no statistical differences with regard to perioperative complications. Comparison of postoperative complication rates across groups revealed a statistically higher rate for the inflatable group. The majority of these complications was constituted by mechanical failure associated with inflatable PPS. Also, the comparison of complication rates in patients with or without DM or history of RPS showed no difference of overall complication rates.

Although semirigid (malleable) PPs are less expensive and more durable, they are disadvantaged in terms of cosmetic appearance due to a constant state of erection. On the other hand, inflatable PPs offer more physiological erections but may lead to mechanical failure in the postoperative period. In the literature, mechanical failure rates vary from $0-5 \%$ for semirigid (malleable) PPs to $23 \%$ for inflatable PPs $(2,3,10,13)$. A study conducted by Lotan et al. reported that the complication-free rate was $87 \%$ for semirigid (malleable) PPs, whereas it was 50\% for inflatable PPs (19). In our study, while no difference was detected between the groups with regard to perioperative complications, a statistically higher postoperative complication rate was determined in the inflatable group (21\%) compared to the semirigid (malleable) group (6.4\%). Half of the postoperative complications in the inflatable group were accounted by mechanical failure.

In the literature, whether post-PPI infective complications are more prevalent among patients with DM has been controversial. Although there are publications that corroborate the role of DM as a risk factor for postoper- 
ative infections, there are also contradictory studies. Penidri et al. stated in their metanalysis that DM could be a risk factor for PP infection, although this could not be completely clarified (15). The relation of RPS history with perioperative and postoperative complication rates has also been contended in the literature. In a study by Cuneyd et al., erosion rates in semirigid (malleable) PPs were higher in the RPS group, compared to patients with other comorbidities, however, postoperative complication rates were reported to be similar across groups. They connected these high erosion rates to fibrosis that develops in the cavernosal tissue after RPS (10). On the other hand, in a study by Lane et al., it was stressed that three-piece PP surgery had comparable postoperative complication rates in patients with and without RPS history, and therefore, could be utilized safely in these patients (17). In our study, there were no differences between patients with and without DM and between patients with and without history of RPS with regard to perioperative and postoperative complication rates.

The limitations of our study include its dependence on retrospective data, lack of partner satisfaction data as it could not be evaluated for all patients, and absence of long-term follow up data of patients.

\section{Conclusions}

PPI surgery has been performed worldwide in the treatment of ED, on patients who do not respond to oral and intracavernosal therapies. Although inflatable PPs possess a more cosmetic and physiological structure, they cannot be used in all patients in our country due to their higher cost and the reimbursement conditions of our social security system. Semirigid (malleable) PPs constitute the most commonly utilized PPs at our clinic despite certain disadvantages. In conclusion, we determined in this study that semirigid (malleable) PPs were associated with lower complication rates compared to the inflatable group, particularly with regard to mechanic failure, and that DM and history of RPS did not make a difference in complication rates in patients planned to undergo PPI.

\section{REFERENCES}

1. Evans C. The use of penile prostheses in the treatment of impotence. Br J Urol. 1998; 81:591-8.

2. Natali A, Olianas R, Fisch M. Penile implantation in Europe: successes and complications with 253 implants in Italy and Germany. J Sex Med. 2008; 5:1503-1512.

3. Atienza Merino G. Penile prosthesis for the treatment of erectile dysfunction. Actas Urol Esp. 2006; 30:159-69.

4. Lux M, Reyes-Vallejo L, Morgentaler A, et al. Outcomes and satisfaction rates for the redesigned 2-piece penile prosthesis. J Urol. 2007; 177:262-266.

5. Levine LA, Estrada CR, Morgentaler A. Mechanical reliability and safety of, and patient satisfaction with the Ambicor inflatable penile prosthesis: results of a 2 center study. J Urol. 2001; 166:932937.

6. Gentile G, Franceschelli A, Massenio P, et al. Patient's satisfaction after 2-piece inflatable penile prosthesis implantation: an Italian multicentric study. Arch Ital Urol Androl. 2016; 88:1-3.
7. Trost L, Hellstrom WJ. History, contemporary outcomes, and future of penile prostheses: a review of the literature. Sex Med Rev. 2013; 1:150-163.

8. Henry GD, Karpman E, Brant W, et al. The who, how and what of real-world penile implantation in 2015: the PROPPER registry baseline data. J Urol. 2016; 195:427-433.

9. Menard J, Tremeaux JC, Faix A, et al. Erectile function and sexual satisfaction before and after penile prosthesis implantation in radical prostatectomy patients: a comparison with patients with vasculogenic erectile dysfunction. J Sex Med. 2011; 8:3479-3486.

10. Sevinc C, Ozkaptan O, Balaban M, et al. Outcome of penile prosthesis implantation: are malleable prostheses an appropriate treatment option in patients with erectile dysfunction caused by prior radical surgery? Asian J Androl. 2017; 19:477-481.

11. Anafarta K, Safak M, Beduk Y, et al. Clinical experience with inflatable and malleable penile implants in 104 patients. Urol Int. 1996; 56:100-104.

12. Scherzer ND, Dick B, Gabrielson AT, et al. Penile prosthesis complications: planning, prevention, and decision making. Sex Med Rev. 2019; 7:349-359.

13. Ko OS, Bennett NE Jr. Ambicor two-piece inflatable penile prosthesis: background and contemporary outcomes. Sex Med Rev. 2018; 6:319-327.

14. Levine LA, Estrada CR, Morgentaler A. Mechanical reliability and safety of, and patient satisfaction with the Ambicor inflatable penile prosthesis: results of a 2 center study. J Urol. 2001; 166:932-7.

15. Pineda M, Burnett AL. Penile prosthesis infections - A review of risk factors, prevention, and treatment. Sex Med Rev. 2016; 4:389398.

16. Bishop JR, Moul JW, Sihelnik SA, et al. Use of glycosylated hemoglobin to identify diabetics at high risk for penile periprosthetic infections. J Urol. 1992; 147:386-388.

17. Lane BR, Abouassaly R, Angermeier KW, et al. Three-piece inflatable penile prostheses can be safely implanted after radical prostatectomy through a transverse scrotal incision. Urology. 2007; 70:539-42.

18. Chung E. Penile prosthesis implant: scientific advances and technological innovations over the last four decades. Transl Androl Urol. 2017; 6:37-45.

19. Lotan Y, Roehrborn CG, McConnell JD, et al. Factors influencing the outcomes of penile prosthesis surgery at a teaching institution. Urology. 2003; 62:918-21.

\section{Correspondence}

Erdem Kisa, MD, FEBU (Corresponding Author)

drerdemkisa@hotmail.com

Mehmet Zeynel Keskin, MD

zeynel_akd@hotmail.com

Cem Yucel, MD

meclecuy@hotmail.com

Murat Ucar, MD

drmuratucar@hotmail.com

Okan Yalbuzdag, MD

drozgurcakmak577@yahoo.com

Yusuf Ozlem Ilbey, MD

ozlemyusufilbey@hotmail.com

Tepecik Training and Research Hospital, Urology Department,

Yenişsehir Mah, Gaziler Cad. No:468, Konak/Izmir (Turkey) 